\title{
Perspectivas e ações de diferentes atores sociais na gestão e sustentabilidade do turismo em Vargem (SP)
}

\author{
Perspectives and actions of different social actors in the management and \\ sustainability of tourism in Vargem (SP, Brazil)
}

\section{Cristiane Ferraz e Silva Suarez, Nayra de Moraes Gonçalves, João Luiz de Moraes Hoefel}

\begin{abstract}
RESUMO
Este trabalho originou-se da constatação de que a área de estudo, o município de Vargem (SP), vem apresentando diversos problemas, principalmente relacionados ao desenvolvimento do turismo de forma desordenada, decorrentes de variadas alterações socioambientais regionais. O fato de o município estar inserido em uma Unidade de Conservação, a Área de Proteção Ambiental do Sistema Cantareira, enfatiza a necessidade de estudos que contribuam para a elaboração de políticas públicas que possam embasar planos turísticos sustentáveis aliados à conservação dos recursos naturais. Desta forma, este trabalho teve como objetivo identificar perspectivas e ações de diferentes atores sociais na gestão e sustentabilidade do turismo no município. Visando contemplar os objetivos propostos foram adotados procedimentos metodológicos que envolveram levantamentos bibliográficos, trabalhos de campo, nos quais foram realizadas entrevistas e aplicação questionários semiestruturados, bem como a posterior análise dos dados. Os resultados obtidos possibilitaram apresentar uma discussão sobre turismo na visão dos diferentes atores sociais entrevistados e as estratégias e ações existentes para o turismo sustentável e a conservação ambiental em Vargem.
\end{abstract}

PALAVRAS-CHAVE: Gestão; Sustentabilidade; Turismo; Atores Sociais.

\section{ABSTRACT}

This research was developed due to the perception that the study area, the municipality of Vargem (SP, Brazil), has shown several problems, mainly related to tourism development in a disorderly manner, resulting in a variety of regional socioenvironmental changes. The fact that the municipality is inserted in a Conservation Area, the Cantareira System Environmental Protected Area, reinforces the necessity of studies which contribute to the creation of public policies that can support sustainable tourism plans, associated with the conservation of natural resources. Thus, this study aimed to identify different perspectives and actions of diverse social actors in the management and sustainability of tourism in Vargem. Aiming to reach the proposed goals methodological procedures were adopted involving literature surveys, field work, interviews, and the application of semi-structured questionnaires, and the subsequent data analysis. The results allowed to present an analysis of local tourism based on the vision. of the different social actors interviewed and the existing strategies and actions to develop sustainable tourism and environmental conservation in Vargem.

KEYWORDS: : Management; Sustainability; Tourism; Social Actors. 


\section{Introdução}

O planejamento e a gestão do turismo vêm apresentando-se como uma grande preocupação para todos os profissionais interessados na sustentabilidade da atividade. Tal preocupação se fundamenta nos inúmeros exemplos de impactos socioambientais, econômicos e culturais negativos existentes em todo o mundo, decorrentes do crescimento desordenado da atividade turística (SEABRA, 2001).

Torna-se cada vez mais importante promover pesquisas sobre os efeitos da atividade turística na sociedade, tornando-se necessárias propostas de turismo sustentável. Para Gunn (2002) o conceito de turismo sustentável aponta a necessidade de um maior equilíbrio territorial, ambiental e econômico para o desenvolvimento da atividade, requerendo novas abordagens dos setores públicos e privados.

A adoção dos princípios da sustentabilidade pelo turismo, pode transformá-lo em uma atividade com propósitos de crescimento pessoal e comunitário, em prol do bem-estar comum, pela conservação de meio ambiente. Para Ruschmann (2008, p.109), os conceitos turismo e sustentabilidade estão intimamente ligados pois, "encontrar o equilíbrio entre os interesses econômicos que o turismo estimula e um desenvolvimento da atividade que preserve o meio ambiente não é tarefa fácil."

Townsend; Begon e Harper (2006) apontam que uma atividade pode ser considerada sustentável se for continuada ou repetida em um futuro previsível, sem causar danos a sociedade e ao ambiente e, para os autores, a preocupação surge porque grande parte das atividades humanas são insustentáveis.

Dias (2003) cita alguns dos elementos chave da sustentabilidade turística, como por exemplo: a satisfação das necessidades dos visitantes e das comunidades receptoras e a proteção e o melhoramento do atrativo turístico para o futuro por ser parte de um recurso econômico nacional. A relação entre os turistas, as comunidades anfitriãs, os atrativos e o meio ambiente compreende um conjunto complexo de elementos interativos. Cabe reforçar, entretanto, que cada um dos elementos deve manter sua própria continuidade em simbiose com os demais mediante o desenvolvimento de uma relação mutuamente benéfica.

Para Irving et al. (2005), a promoção do turismo sustentável requer uma concepção estratégica e duradoura de desenvolvimento, amparada por um novo olhar sobre as questões sociais, culturais e ambientais dos destinos, aliadas e em interação com a economia globalizada. A Organização Mundial do Turismo - OMT (2001) afirma a necessidade de uma participação ampla, ressaltando que o setor turístico privado também deve cooperar em sua execução, assim como as comunidades locais e os turistas.

Neste cenário, este trabalho teve como objetivo identificar perspectivas e ações de diferentes atores sociais na gestão e sustentabilidade do turismo no município de Vargem, APA do Sistema Cantareira - SP. A análise destas questões no município mostra-se interessante, pois o mesmo vem passando por um processo de urbanização e incremento turístico sem planejamento, responsáveis pelo aumento de impactos e transformações socioambientais locais. Esta situação demanda a realização de estudos que possibilitem a elaboração de planos turísticos sustentáveis e a implementa- 
ção de diversas políticas públicas que permitam a gestão e sustentabilidade do turismo e dos recursos naturais locais.

Dias (2003) define políticas públicas como o conjunto de ações executadas pelo Estado, enquanto sujeito, dirigidas a atender às necessidades de toda a sociedade. Podem ser compreendidas como linhas de ação que buscam satisfazer ao interesse público e têm que estar direcionadas ao bem comum. Contudo, os dois grandes desafios de toda politica pública são a construção de decisões que agreguem consenso entre os diferentes atores sociais e assegurar que as decisões tomadas serão implantadas (RUA, 2006).

Política pública de turismo é compreendida por Cruz (2000) como um conjunto de intenções, diretrizes e estratégias estabelecidas no âmbito do poder público, em virtude do objetivo geral de alcançar o pleno desenvolvimento da atividade turística em determinada localidade. Para Beni (2001), as políticas de turismo são orientações específicas para a gestão diária do turismo, abrangendo os muitos aspectos operacionais da atividade. Neste sentido, uma política de turismo não deve estar voltada apenas para o desenvolvimento do setor, mas deve ser compreendida dentro de um contexto mais geral de uma política pública de desenvolvimento, além de contar com a participação da iniciativa privada e da sociedade civil, a fim de estimular a prática contínua e qualificada da atividade.

Neste contexto, o crescimento acelerado do turismo em áreas protegidas tem gerado debates e posturas divergentes quanto às dificuldades concretas de integrar as políticas públicas do turismo às políticas de gestão ambiental e urbanização. De um modo geral essas políticas têm se mostrado conflitantes e, teoricamente, visam conciliar os interesses econômicos, a preservação e conservação ambiental, considerando os interesses das populações autóctones, com o objetivo de reduzir os impactos negativos sobre o meio ambiente, como também manter essas populações no seu lugar de origem (FADINI; HOEFFEL; SUAREZ, 2007).

Outro aspecto a ser considerado na elaboração de políticas públicas é a participação da sociedade. Nos vários níveis em que possa ocorrer a implementação de uma política pública para o turismo, diversos atores devem ser considerados, inclusive as ONGs, que podem contribuir com resultados mais efetivos da ação governamental.

Dodds e Butler (2009) concordam com esta visão afirmando que a chave para a implementação de políticas bem sucedidas é atribuir mais ênfase a participação local no planejamento das mesmas e sugerem a necessidade de um papel mais integrado entre as políticas de turismo e os múltiplos atores sociais envolvidos no processo, tanto do setor público como privado. Poles e Rabinovici (2010) lembram ainda que um dos maiores desafios para as políticas públicas que regem o turismo é compatibilizar a participação democrática e representativa das comunidades locais na criação e gestão destas políticas.

O termo "governança" pode ser entendido como a capacidade que os governos têm de criar condições e de responder às demandas da sociedade. Em se tratando da governança social ou governança democrática, essa capacidade de governar pressu- 
põe uma administração participativa que envolve as populações locais na elaboração, monitoramento e, em alguns casos, na execução de políticas públicas (BRASIL, 2007).

É importante que a governança tenha como base a transparência e a representatividade dos setores envolvidos com a atividade, deve ocorrer de maneira participativa e compartilhada e definir uma dinâmica de papéis e interações entre os membros da organização, de maneira a desenvolver a participação e o engajamento no processo de decisão. O processo de sensibilização e mobilização dos atores envolvidos, principalmente da comunidade autóctone é essencial.

\section{Caracterização da área de estudo}

O município de Vargem, área de estudo do presente trabalho, está situado na Região Bragantina, a 97 km da capital São Paulo, as margens da Rodovia Fernão Dias, e da Serra da Mantiqueira. Faz divisa com estado de Minas Gerais confrontandose com o município de Extrema (Figura 1).

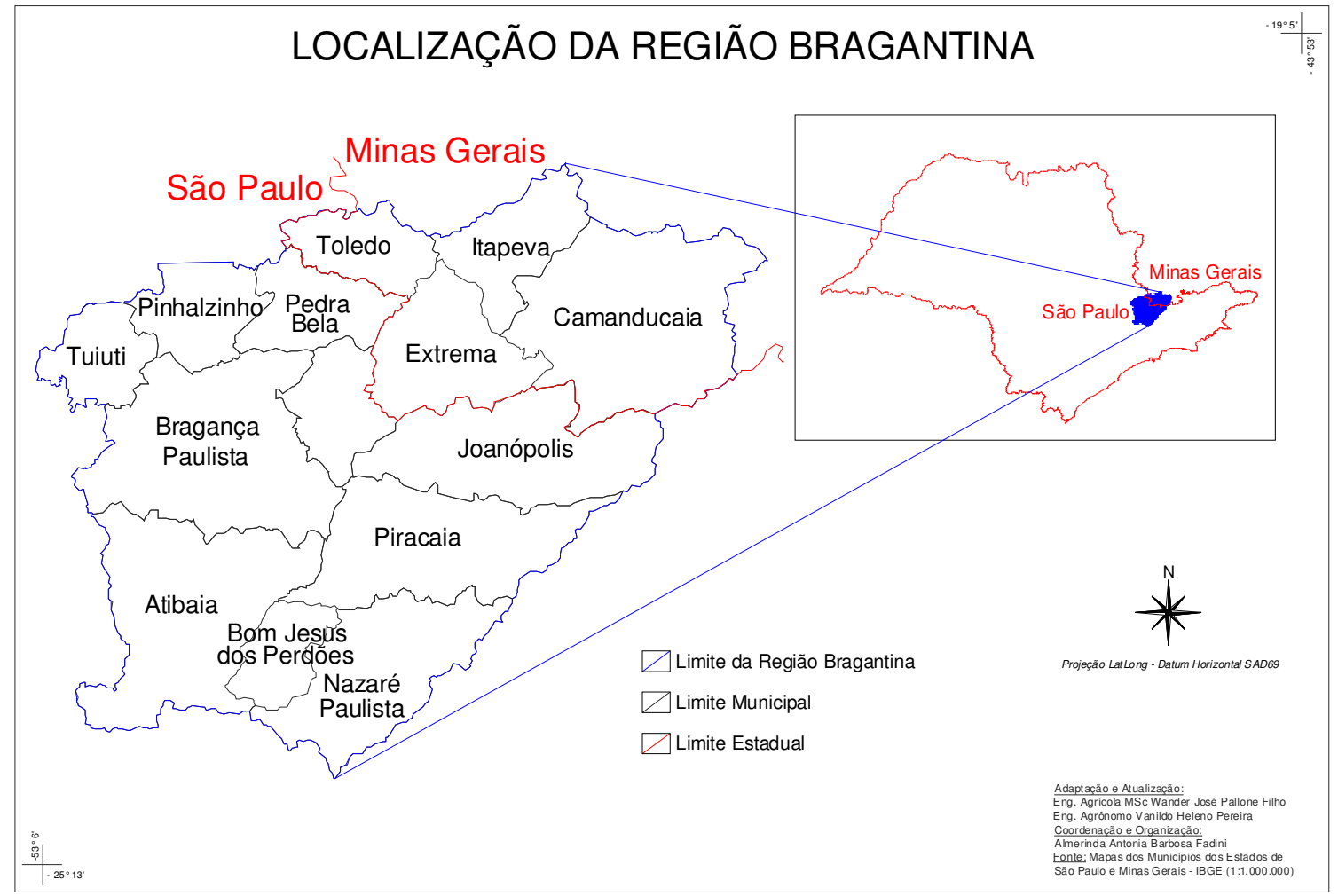

Figura 1: localização do município de Vargem. Fonte: Adaptado do IBGE.

Figure 1: Location of the municipality of Vargem. Source: Adapted from IBGE.

Atualmente no município existem apenas alguns remanescentes de cobertura vegetal nativa concentrados basicamente nas áreas de maior altitude, em especial na 
Serra do Lopo, Serra de Itapetinga, Serras do Arraial, Anhumas e Araras, nas quais ainda encontra-se espécies de fauna e flora características da biodiversidade regional (SILVA et al., 1994) Observa-se que os campos antrópicos predominam neste município em função dos processos econômicos intensivos aos quais esta área foi submetida. Seu perímetro abrange a sub-bacia do Rio Jaguari e do Rio Camanducaia, formadores dos reservatórios Jaguari-Jacareí e, além disso, abriga a cabeceira do Rio Juqueri-Mirim formador do reservatório Paiva Castro. Todos esses reservatórios integram o Sistema Cantareira.

O município integra a APA do Sistema Cantareira, criada a partir da Lei Estadual №. 10.111 de dezembro de 1998, que abrange também os municípios de Atibaia, Bragança Paulista, Joanópolis, Mairiporã, Nazaré Paulista e Piracaia (SÃO PAULO, 2000). Esta APA tem como objetivos, além de garantir a conservação do conjunto paisagístico e da cultura regional, a manutenção e melhoria da qualidade da água, especialmente nos municípios do entorno dos reservatórios dos Rios Jaguary/Jacareí do Sistema Cantareira, que abastecem a Região Metropolitana de São Paulo (RMSP) e regulam o fluxo de água para a Região Metropolitana de Campinas. A APA do Sistema Cantareira é uma Unidade de Conservação ainda em fase de regulamentação, fato que vem intensificando uma problemática ambiental centrada no parcelamento do solo e na conservação de recursos hídricos.

Em função do acesso facilitado a esta região através das Rodovias $D$. Pedro I e Fernão Dias, esta APA vem se tornando alvo de empreendimentos imobiliários diversos, consolidando um processo crescente de ocupação do solo e uso turístico desordenado. Esta expansão urbana, estimulada pelo crescimento da Região Metropolitana de São Paulo rumo a Região Bragantina, e por políticas municipais de incremento urbano, vem ocorrendo de forma intensa e caracteriza-se pela proliferação de loteamentos de alta densidade populacional, implantados sem uma adequada infraestrutura. Dos usos identificados, os mais dinâmicos, impactantes e transformadores são os associados aos processos turísticos e de urbanização (HOEFFEL et. al., 2005).

Neste cenário, a restrição espacial, a cobertura vegetal e os incentivos fiscais restringem o desenvolvimento industrial fazendo da atividade turística, na visão dos gestores e empresários locais, uma das poucas alternativas econômicas possíveis no município. No entanto, verifica-se que esta atividade ainda necessita de planejamento e de políticas públicas adequadas capazes de preservar o patrimônio ecológico, além de maior envolvimento da população local, visando a gestão sustentável do turismo no município.

\section{Metodologia}

Os procedimentos metodológicos utilizados na elaboração deste trabalho envolvem levantamento bibliográfico, pesquisa quanti-qualitativa junto à população local e pesquisa qualitativa exploratória com diferentes atores sociais ligados ao Poder Público, a Sociedade Civil Organizada e a Iniciativa Privada de Vargem. 
Foi realizada uma pesquisa junto à população local a fim de possibilitar a obtenção das respostas das questões enunciadas. Trata-se de uma pesquisa de caráter descritivo onde os fatos foram observados, registrados, analisados, classificados e interpretados por meio de técnicas de coleta de dados como questionários e observação sistemática que, segundo Dencker (2001), pressupõe uma delimitação precisa do campo a ser investigado, tanto no tempo quanto no espaço. Desta forma, foram entrevistados 91 moradores locais, com diferentes perfis socioeconômicos, escolhidos aleatoriamente, distribuídos nos diferentes bairros do município, tanto da área rural quanto urbana. Como instrumento de pesquisa foi utilizado um questionário estruturado, com um roteiro de entrevista composto por 13 questões alternadas entre abertas e fechadas para a obtenção de dados mais objetivos que possibilitaram a confirmação ou rejeição das hipóteses, e neste trabalho serão apresentadas e analisadas as questões mais pertinentes aos objetivos estabelecidos. O questionário foi embasado na metodologia proposta por Dencker (2001) e Ruschmann (2008), que afirmam a importância das perguntas estimularem a memória do entrevistado, sendo ordenadas em seqüência lógica, iniciando com informações socioeconômicas a fim de criar um ambiente de familiaridade entre entrevistador e entrevistado.

A aplicação desses questionários teve como objetivo obter o perfil socioeconômico dos entrevistados e analisar as perspectivas destes com relação ao processo de desenvolvimento turístico no município.

$\mathrm{Na}$ pesquisa com os atores locais foi realizado um levantamento das lideranças, utilizando a técnica do tipo "bola de neve", apresentada por Becker (1994), em que o entrevistado indica outros.

Esta pesquisa foi realizada por meio de entrevistas semiestruturadas, através da utilização de um roteiro composto por 21 questões destinadas aos três grupos estudados (poder público, iniciativa privada e sociedade civil organizada) e mais 06 questões aplicadas especificamente aos empresários do setor hoteleiro (totalizando 26 questões respondidas por estes empresários), das quais serão apresentadas as consideradas mais pertinentes ao tema proposto.

Do Poder Público foram entrevistados 08 gestores em exercício no ano de 2010: a Prefeita do Município de Vargem, o Assessor de Gabinete da Prefeitura, a Diretora do Departamento de Educação, a Diretora do Departamento de Saúde, o Diretor do Departamento de Planejamento, o Chefe da Seção de Gestão Ambiental, o Diretor da Agricultura e Abastecimento e o Presidente da Câmara Municipal de Vargem.

Dentre os representantes da iniciativa privada foram realizadas 04 entrevistas com gerentes e proprietários de hotéis e pousadas locais, representando o setor hoteleiro, 02 com empresários que mais se destacam no ramo de alimentos e bebidas e um com o representante da Companhia de Saneamento Básico do Estado de São Paulo (SABESP).

Foram entrevistados também 03 atores sociais da sociedade civil organizada, atuantes em Organizações Não Governamentais.

Para um melhor entendimento dos dados adquiridos com a realização das en- 
trevistas, os atores sociais foram agrupados em Grupo 1, Grupo 2 e Grupo 3, sendo respectivamente correspondente ao Poder Público, a Iniciativa Privada e a Sociedade Civil Organizada.

\section{Resultados}

\section{A perspectiva dos moradores locais}

O objetivo da primeira parte do questionário foi identificar o perfil socioeconômico dos moradores locais de Vargem, através de questões sobre os dados gerais dos entrevistados.

Em uma breve análise deste perfil verificou-se que a população do município é composta por residentes tradicionais e de migrantes, em sua maioria do estado de São Paulo. Quanto à faixa etária dos entrevistados, em sua maioria, correspondem a uma população jovem e ativa, com 51,6\% com idade entre 21 a 40 anos. Houve uma frequência igualitária em relação ao sexo dos entrevistados com 50,5\% do sexo feminino e $49,5 \%$ masculino. A maioria dos entrevistados $(52,8 \%)$ é casada. Quanto à escolaridade, $33 \%$ dos entrevistados completou o Ensino Médio, uma parcela significativa de $23 \%$ não terminou o Ensino Fundamental e apenas 7,7 \% possui nível Superior completo.

Um aspecto interessante a ressaltar é que, principalmente para os jovens, não há disponibilidade suficiente de emprego, com exceção aos relacionados às atividades tradicionais do município como a agricultura, pecuária, olaria e carvoaria, e esta mão de obra necessita ser alocada nos municípios vizinhos, principalmente ExtremaMG e Bragança Paulista-SP. A renda mensal familiar predominante $(70,2 \%)$ é de até 03 salários mínimos (cabe ressaltar que no período de realização das entrevistas o salário mínimo base era de $\mathrm{R} \$ 465,00)$.

A segunda parte do questionário buscou verificar as perspectivas da população local sobre o turismo no município.

Acerca da importância da implantação de um projeto turístico em Vargem, a maioria dos entrevistados $(84,6 \%)$ considera importante, justificando principalmente que o mesmo incrementa a economia local, desenvolve e divulga o município e gera empregos.

Verifica-se que os moradores locais ressaltam os benefícios econômicos que o desenvolvimento da atividade turística pode gerar, fato que pode ser justificado devido a baixa oferta de empregos no município, o que ocorre, principalmente, pelas restrições ambientais pelas quais o mesmo está sujeito, já que grande parte de sua área corresponde à Área de Preservação Permanente (APP) e que, por estar inserido na APA do Sistema Cantareira, as atividades industriais são restritas.

Uma das justificativas às respostas negativas foi o aumento do custo de vida local ocasionado pelo turismo, o que de fato pode ocorrer caso a atividade turística desenvolva-se de forma espontânea e desorganizada. Portanto, reitera-se a importância da elaboração de um projeto turístico que possa minimizar os efeitos negativos e 
ordenar a atividade.

Sobre a compreensão do conceito de turismo sustentável, a maioria não soube responder, evidenciando a necessidade da adoção de programas de conscientização sobre o conceito, direcionado à comunidade local. No entanto, ainda que as respostas não acompanhem exatamente o que literatura na área considera como turismo sustentável, algumas respostas apresentaram alguns componentes que integram o conceito, considerando pertinente o desenvolvimento do mesmo no município.

Quando questionados sobre os benefícios que o turismo pode gerar para Vargem, os principais pontos citados foram de ordem econômica, como a geração de empregos, o aumento da renda e favorecimento do comércio local, entretanto, alguns autóctones disseram não trazer nenhum benefício. Estas repostas podem representar a falta de conhecimento sobre as possibilidades que o turismo pode gerar no destino ou até mesmo a falta de conhecimento do potencial turístico do município.

Neste sentido, é importante ressaltar, conforme mencionado anteriormente, que a sustentabilidade turística envolve, entre diversos fatores, uma relação adequada entre comunidades receptoras e turistas capaz de gerar oportunidades econômicas e que ao mesmo tempo contribua para a conservação socioambiental na localidade (DIAS, 2003; IRVING et al, 2005; RUSCHMANN, 2008).

\section{A perspectiva dos atores sociais}

Como forma de identificar e conhecer o perfil socioeconômico dos atores sociais que atuam no Poder Público (Grupo 1), na Iniciativa Privada (Grupo 2) e na Sociedade Civil Organizada (Grupo 3) no município de Vargem, a primeira parte do questionário contempla questões referentes à procedência, idade, sexo, estado civil e escolaridade dos entrevistados.

Com relação à procedência, foi possível identificar que a maioria dos entrevistados do Grupo 1 (75\%) nasceu no próprio município, já a maioria dos entrevistados dos Grupos 2 e 3 nasceram em outras cidades do estado de São Paulo. Quanto à faixa etária, a maioria dos três grupos entrevistados tem idade entre 41 a 65 anos com $62,50 \%, 57,14 \%$ e $66,67 \%$ respectivamente.

Com relação ao sexo dos entrevistados houve a predominância do sexo masculino, com 62,50\% do Grupo 1, 71,43\% do Grupo 2 e 100\% do Grupo 3. A maioria dos atores sociais entrevistados do Grupo 1 (87,5\%), do Grupo 2 (57,14\%) e todos do Grupo 3 são casados. Quanto ao grau de escolaridade, a maioria dos entrevistados do Grupo 1 (50\%), Grupo $2(57,14)$ e Grupo 3 (66,67\%) possuem Ensino Superior completo.

A segunda parte do questionário foi estruturada com questões que contribuíram para verificar e analisar as perspectivas e a participação dos atores sociais na gestão e sustentabilidade do turismo na localidade.

A maioria dos entrevistados do Grupo 1 (75\%), Grupo $2(57,14 \%)$ e Grupo 3 $(66,67 \%)$ consideram que as atividades turísticas em Vargem têm influenciado a qua- 
lidade de vida dos moradores locais com o aumento da economia local, da renda e dos empregos no município. Já $25 \%$ do Grupo 1 afirmou que a demanda turística atual não é significativa ao ponto de influenciar a qualidade de vida dos autóctones. Os entrevistados do Grupo 2 e do Grupo 3 acrescentaram ainda que os comerciantes possuem uma visão distorcida do que é a atividade turística e como ela pode beneficiar a população local.

Quanto a motivação do turista para visitar Vargem, a maioria dos entrevistados do Grupo 1 respondeu que é devido a tranquilidade e sossego do município, já os entrevistados do Grupo 2 e do Grupo 3 responderam em sua maioria que é em função os atrativos naturais.

A maioria dos entrevistados de todos os Grupos destacou que a atividade turística em Vargem proporciona desenvolvimento econômico, cultural e social. A geração de empregos também foi um item citado por diversos atores sociais, demonstrando que atividade turística em Vargem é vista como uma das possibilidades de desenvolvimento socioeconômico.

Quando questionados sobre o interesse do turista pela cultura local, a maioria dos entrevistados do poder público respondeu que o turista tem interesse, principalmente, pelas festas religiosas e igrejas locais, mas grande parte dos atores sociais da iniciativa privada e da sociedade civil organizada acredita que o turista não tem conhecimento dos atrativos culturais devido á falta de divulgação dos mesmos, e que, na maioria das vezes, ficam restritos aos meios de hospedagem.

Foi solicitado também aos entrevistados que apontassem os principais problemas de Vargem, e, de acordo com os atores sociais entrevistados, os mais significativos são a falta de recursos para implantação de projetos e realização de eventos no município, a falta de oportunidade de empregos, o sistema precário de saúde e a falta de participação e interesse dos próprios munícipes nas discussões sobre as ações para a cidade.

Para os atores sociais Vargem não apresenta problemas significativos decorrentes da atividade turística, pelo fato da mesma ainda ser incipiente, mas destacam o aumento da quantidade de lixo, principalmente em algumas trilhas e cachoeiras. Destacaram também que o comércio local não está preparado para atender os turistas e que falta um Centro de Informações Turísticas na entrada da cidade, bem como a divulgação da mesma na região.

Os relatos colhidos apontam que todos os atores sociais entrevistados consideram importante a implantação de um Projeto Turístico para Vargem, atribuindo a este a função de alavancar e desenvolver o município e organizar a realização de uma atividade turística sustentável, principalmente considerando que a maioria dos atrativos são naturais e precisam ser explorados de forma não predatória.

Os entrevistados foram estimulados a apresentar algumas propostas para 0 turismo em Vargem, sendo que as que mais se destacaram foram as de investimentos na infraestrutura turística, principalmente em hotéis e restaurantes na área urbana e rural, de maior divulgação do município e seus atrativos, de criação de um centro de 
artesanato municipal que capacite a população local e incentive o desenvolvimento desta atividade, da exploração dos atrativos naturais de forma não predatória e por fim, da criação de rotas de turismo rural, envolvendo os turistas em visitas a fazendas antigas e a propriedades de cultivo orgânico.

Além disso, foi destacada também a importância de se estabelecer parcerias entre empresários, população e Gestão Pública para a implantação de ações voltadas ao desenvolvimento turístico sustentável em Vargem.

Estas questões reforçam a importância da adoção de estratégias que motivem a participação da sociedade local, com destaque para os diferentes atores sociais, na elaboração de políticas públicas para o turismo em todos os seus níveis, desde o diagnóstico até a implementação e avaliação (OMT, 2001; DODDS; BUTLER, 2009). Conforme mencionado por Poles e Rabinovici (2010), estimular e concretizar esta participação apresenta-se como um dos maiores desafios para as políticas públicas de turismo.

\section{Ações de diferentes atores sociais na gestão e sustentabilidade do turismo em Vargem}

A partir das entrevistas foi possível detectar que entre os atores sociais entrevistados, 87,50\% do Grupo 1, 42,86\% do Grupo 2 e 100\% do Grupo 3 têm conhecimento sobre algumas ações/estratégias para o desenvolvimento do turismo sustentável em Vargem, sendo as ações realizadas pela UNICIDADES, em função do Circuito Entre Serras e Águas, as mais conhecida pelos atores sociais, seguidas pelos projetos FAPESP realizados pelo CEA - Universidade São Francisco e pelo NEPAM - Unicamp, que aconteceram no período de 2009 a 2011. Também foram mencionadas as ações da CATI - Coordenadoria de Assistência Técnica Integral - relacionadas ao turismo rural, cursos promovidos pelo Fundo Social, cursos técnicos de Desenvolvimento Turístico e de Meio Ambiente financiados pelo Ministério do Turismo e o Projeto Ponto de Cultura do Ministério da Cultura, além de algumas ações realizadas dentro de hotéis e pousadas e pelas associações.

Todos os entrevistados do Grupo 2 e do Grupo 3 responderam que participam ou estão inseridos no desenvolvimento ou execução dessas ações/estratégias, assim como a maioria $(85,71 \%)$ dos atores sociais entrevistados do Grupo 1. A participação destes atores acontece principalmente nas reuniões e ações realizadas pela UNICIDADES e através da Gestão Pública, na gestão das ações e na elaboração de projetos.

De acordo com os atores sociais do Grupo 1 (85,71\%) e do Grupo 2 (50\%), a maioria das ações/estratégias citadas associam o desenvolvimento turístico com a conservação dos recursos naturais locais e/ou regionais. Como exemplo foram citados o envolvimento da CATI com a questão ambiental em suas ações, principalmente no meio rural e os projetos da FAPESP que buscaram analisar justamente estas questões, as propostas de curso de meio ambiente ligadas ao turismo, visando à conscientização da sustentabilidade para o município, as ações na área da educação ambiental e projetos que envolvem os alunos desde a pré-escola. 
Já $66,67 \%$ dos atores sociais do Grupo 3 acreditam que não e justificam a resposta ressaltando a necessidade de maior integração da Gestão Pública com as ações da UNICIDADES, bem como a necessidade de integração das câmaras técnicas de turismo e meio ambiente na agência de desenvolvimento.

Os relatos dos atores sociais com relação à implementação de ações que estimulem o turismo em Vargem por parte da Gestão Pública atual são polêmicos, uma vez que a maioria $(62,50 \%)$ do Grupo 1, que é composto pelos Gestores Públicos, responderam que a Gestão Pública tem implementado algumas ações neste sentido. Já os entrevistados do Grupo $2(71,43 \%)$, formado pela iniciativa privada, e os entrevistados do Grupo $3(66,67 \%)$, composto por representantes de ONGs responderam que a Gestão Pública não tem realizado ações relacionadas com o turismo no município.

Observa-se, desta forma, a existência de um conflito de percepções e ações entre os atores sociais, principalmente no que tange a questão relacionada à política pública local. Neste sentido, para se alcançar a sustentabilidade turística, é preciso que a atividade seja desenvolvida com o suporte de um adequado planejamento participativo, o qual deverá ser realizado com base em informações provenientes de estudos e análises referentes ao cenário da localidade, bem como das potencialidades de desenvolvimento futuro e envolvimento da comunidade local.

Dentre as ações da gestão pública mencionadas estão a realização de projetos para melhorias na infraestrutura básica e turística, tais como o projeto de criação do teleférico, do parque de lazer municipal, do Portal municipal, do terminal rodoviário, além da organização e participação em eventos turísticos, como a Romaria das águas e esportes radicais como o campeonato paulista de MotoCross, além do Projeto de implantação do Centro de Informações Turísticas e do Projeto "Luzes de natal".

$\mathrm{Na}$ visão dos atores dos Grupos 2 e 3, no entanto, a Gestão Pública não apresenta-se preparada para gerenciar a atividade turística municipal, além de não buscar verbas para este fim.

No que tange a participação da população local nas decisões sobre as ações relacionadas ao turismo, entretanto, parece existir um consenso entre os atores sociais entrevistados, que consideram a população muito apática e pouco participativa e justificaram que realizam a divulgação sobre fóruns, ações e audiências, mas a população não mostra interesse e a grande maioria não comparece.

Esta percepção dos atores se estende também a falta de envolvimento da população nas ações relacionadas às questões ambientais. Uma das dificuldades apresentadas pela gestão pública é o fato do município não ter Conselho Municipal de Defesa ao Meio Ambiente (COMDEMA), nem Conselho Municipal de Turismo (COMTUR) o que dificulta o contato com a população, reiterando a necessidade de reativação destes conselhos para que as ações sejam mais bem articuladas.

Como sugestões para a conservação dos recursos naturais em Vargem foi citado pelos entrevistados dos três grupos de atores sociais a implantação projetos de Educação Ambiental, abordando temas como turismo e meio ambiente. Entrevistados do Grupo 1 mencionaram que seria importante para o município criar legislações específicas 
para a localidade e aumentar a fiscalização pela polícia ambiental e os do Grupo 2 acreditam que é necessário o fomento de parcerias entre iniciativa privada e Gestão Pública para a conservação dos recursos naturais de Vargem. Os entrevistados do Grupo 3 citaram a importância de se realizar trabalhos de conscientização ambiental com os oleiros do município, de reativar o CONDEMA e implantar a coleta seletiva no município.

Quanto à contribuição de cada ator social para a conservação dos recursos naturais locais, os entrevistados, em sua maioria, responderam que já realizam algumas ações de conscientização, gestão ambiental e fortalecimento da cidadania, sempre trabalhando pela causa e reconheceram que podem intensificar estas ações, reciclando os resíduos sólidos, usando a água de forma consciente, não jogando lixo nos rios, denunciando ações predatórias e incentivando o plantio de novas árvores e a não derrubada de matas para a utilização do solo com novas formas de ocupação.

No grupo de organizações não governamentais destaca-se a Associação Entre Amigos de Vargem, que tem por finalidade criar condições para o fortalecimento de atividades associativas, produtivas e promocionais a pessoas carentes de atenção e autoestima. Com relação ao turismo, os membros da associação vêm trabalhando principalmente com a questão ligada ao artesanato local, utilizando em sua maioria a bucha vegetal e sementes como matéria prima e organizando encontros com a comunidade para a disseminação destas práticas, entretanto, reiteram a falta de interesse da maioria dos autóctones em aprender um novo ofício como uma alternativa de renda complementar, principalmente pelo fato do retorno do artesanato ser a longo prazo. Mesmo assim, os membros têm como meta a reativação da construção do barracão da Associação Entre Amigos de Vargem para transformá-lo em um Centro de Artesanato Municipal. A Sociedade Amigos do Rio Acima do Município de Vargem S.A.R.A (Rádio SARA FM) realiza desde 2006 o serviço de radiodifusão comunitária, tornando-a um dos principais veículos de comunicação da localidade. A ONG também foi a responsável pela idealização do projeto Ponto de Cultura junto ao Ministério de Comunicação, que visa à aquisição de equipamentos sonoros e a organização de shows com artistas locais. Outra organização não governamental atuante no município é a Agência de Desenvolvimento Regional - UNICIDADES que possui a proposta de implantação do Circuito Turístico Entre Serras e Águas, uma ação estratégica para o desenvolvimento do turismo regional. O circuito está sendo elaborado pela UNICIDADES, pelo SEBRAE - SP em parceria com as secretarias e departamentos de turismo dos municípios envolvidos e com as instituições de ensino superior, Universidade São Francisco e Universidade de Guarulhos. A UNICIDADES abrange 14 cidades do estado de São Paulo e uma do estado de Minas gerais e tem a missão de mediar o diálogo entre as instâncias públicas e privadas, identificando prioridades estratégicas regionais e articular a viabilidade de execução de programas e projetos nestes municípios.

No âmbito do turismo destaca-se a implantação do Projeto de Desenvolvimento Territorial com Foco no Turismo, através da criação do Circuito Entre Serras e Águas e, para tal, possui uma Câmara Técnica de Turismo, formada por um grupo gestor composto por quatro representantes de cada município envolvido, responsáveis 
pela articulação dos diversos segmentos e entidades de interesse turístico e da comunidade para o desenvolvimento do turismo sustentável no circuito regional.

O objetivo geral é promover o desenvolvimento sustentável do turismo, possibilitando melhorias nas condições socioeconômicas e ambientais do território. Dentre os resultados esperados, destacam-se a intenção de aumentar o fluxo de turistas nos municípios que integram o Circuito; a formatação produtos turísticos atrativos comercializáveis; a formatação de quatro roteiros turísticos no território do Circuito Entre Serras e Águas; aumentar em 10\% o número de refeições vendidas; estruturar cinco pontos de venda de produtos artesanais de qualidade e a implantação de sinalização turística na zona urbana e rural em três municípios do Circuito Entre Serras e Águas;

De acordo com a entrevista com a coordenadora da câmara técnica de turismo da UNICIDADES, as principais dificuldades encontradas para a implantação do projeto em Vargem são a sensibilização da comunidade e da gestão pública e privada sobre a importância da participação do município no circuito e a consequente falta de apoio para a realização das atividades que precisam ser desenvolvidas para tal. Segundo a coordenadora, Vargem se encontra neste momento na fase de elaboração do plano de Marketing do Circuito e estão sendo realizadas visitas dos profissionais da agência de eventos para conhecer os atrativos e coletar demais informações pertinentes para o plano.

Na sua visão, os benefícios que a participação no circuito pode trazer para Vargem estão relacionados à maior visibilidade no contexto regional, a participação do município em eventos importantes da área como o "Revelando São Paulo" e o "Salão do Turismo" sem custos, a consultoria para o desenvolvimento de roteiros turísticos e a realização de cursos de capacitação. A coordenadora ressalta que o papel da Gestão Pública de Vargem no projeto é ajudar na formatação dos roteiros, material de divulgação, fornecer dados sobre o município, disponibilizar recursos humanos para acompanhar as visitas de campo na cidade e reativar o COMTUR (isto ainda não foi feito e é fundamental).

O engenheiro responsável pelo Centro de Educação Ambiental - Observatório de Manaciais, localizado em Vargem, informou que a Companhia de Saneamento Básico do Estado de São Paulo - SABESP vem atuando como parceira na conservação dos recursos hídricos locais, principalmente, abrindo espaço neste centro para a realização de atividades de educação ambiental junto à comunidade, através das escolas em parceria com a gestão publica.

Em relação aos meios de hospedagem, como ação realizada para contribuir com a conservação dos recursos naturais em Vargem, foram citadas o envolvimento dos hóspedes em atividades de reflorestamento dentro da pousada, o investimento em ações relacionadas aos esportes radicais e à educação ambiental com hóspedes durante as trilhas, além de estimular o plantio de árvores na propriedade e a colheita de produtos orgânicos produzidos no local. Um dos gerentes dos hotéis pesquisados informou que o hotel possui tratamento de água e esgoto e que os monitores passam informações sobre preservação ambiental aos hóspedes.

Quanto às pesquisas do Centro de Estudos Ambientais - Sociedades e Naturezas - Universidade São Francisco e Núcleo de Estudos AmbientaisUNICAMP, o envolvimento destas duas Instituições de Ensino Superior aconteceu em 
função dos projetos realizados na região, apoiados pela FAPESP (processos n. 06/60366 -5 ; n. 2007/59833-0 e n.2006/51790-8), da realização da tese de doutoramento de Cristiane Ferraz e Silva Suarez, vinculada ao NEPAM-UNICAMP, cuja pesquisadora também é docente da Universidade São Francisco. Várias ações foram realizadas decorrentes destas parcerias que se estenderam à Prefeitura Municipal de Vargem e a CATI. Dentre as ações, foram realizados encontros para a apresentação dos resultados do trabalho e discussão das propostas com alguns segmentos da sociedade, incluindo instituições governamentais, comunidade acadêmica e organizações não governamentais.

Estes encontros foram extremamente enriquecedores para todos os atores e, em especial, para o fortalecimento do espírito participativo em formulação de políticas públicas que visem à sustentabilidade do turismo em Vargem. Lembrando que cabe aos atores sociais, a partir de sua participação e tomadas de decisão, a exigência da incorporação destas propostas pelo poder municipal.

Verificou-se, portanto, através das pesquisas a existência de um trabalho interdisciplinar que envolve parcerias entre o setor público, a iniciativa privada e a sociedade civil organizada para ações que visam à sustentabilidade do turismo em Vargem, contudo, estas parcerias se mostram um pouco fragilizadas, considerando que seus gestores necessitam dispor de um planejamento turístico bem elaborado que direcione os rumos para o turismo local na perspectiva da sustentabilidade, e de pessoal técnico capacitado para atuar na área do turismo, uma vez que não existe um departamento específico para este segmento na atual estrutura de gestão municipal.

\section{Considerações}

Considerando que esta pesquisa teve como objetivo identificar perspectivas e ações de diferentes atores sociais na gestão e sustentabilidade do turismo no município de Vargem-SP, foram adotados procedimentos metodológicos que incorporaram três fases, sendo a exploratória, o trabalho de campo e a análise dos dados obtidos.

Com relação às ações e estratégias adotadas pelos diferentes atores sociais entrevistados, relacionadas à gestão e a sustentabiliadde do turismo, foi possível observar que o poder público municipal vem participando, ainda que de forma incipiente, no desenvolvimento do turismo local.

Destaca-se também a importância dos gestores municipais buscarem parcerias com os empresários da localidade e da região, principalmente os relacionados à oferta turística, e com as associações e ONGs preocupadas com a conservação dos recursos naturais locais, uma vez que a problemática ambiental é evidente na região, somada ao fato do município estar inserido dentro de uma Área de Proteção Ambiental - a APA Cantareira.

Outra questão é a constatação, por meio da pesquisa com os moradores locais que, embora algumas ações já estejam acontecendo, elas não têm se dado de forma integrada entre o poder público e a comunidade local. Esta questão, no entanto, é um pouco polêmica, pois segundo os diferentes atores sociais entrevistados, a população não se motiva a participar e discutir as ações direcionadas ao turismo e ao meio ambiente no município, fato que dificulta esta integração. Do ponto de vista da comunidade local, a gestão 
pública não envolve a população no processo de tomada de decisão.

Quando se almeja realizar atividades turísticas dentro de uma Área de Proteção Ambiental, entretanto, tem que se pensar em ações e práticas sustentáveis no que se refere aos recursos naturais, no bem estar e na qualidade de vida dos moradores e dos turistas que ali visitam.

Desta forma, para que a gestão da atividade turística em Vargem se desenvolva dentro dos critérios da sustentabilidade, necessita-se de práticas que incorporem a integração e o estímulo à participação de todos os atores sociais envolvidos, considerando os arranjos produtivos locais e respeitando as singularidades com vistas aos benefícios para a comunidade. Isto requer a participação tanto do poder público quanto da iniciativa privada e da comunidade local.

\section{Referências bibliográficas}

BECKER, H.S. Métodos de Pesquisa em Ciências Sociais. São Paulo: Hucitec, 1994.

BENI. M. C. Análise Estrutural do Turismo. 2ª ed. São Paulo: Senac, 2001.

CRUZ, R. C.A. Política de turismo e território. São Paulo: Contexto, 2000.

DENCKER, A F.M.; CHUCID da VIÀ, S. Pesquisa empírica em ciências humanas. São Paulo: Futura, 2001.

DIAS, R. Turismo sustentável e meio ambiente. São Paulo: Atlas, 2003.

DODDS, R.; BUTLER, R. W. Inaction More than Action: Barries to the implementation of Sustainable Tourism Policies. In: GOSSLING, S.; HALL, M.C. WEAVER, D.B. Sustainable tourism futures: perspectives on systems, restructuring, and innovations. New York and London: Routledge, 2009.

FADINI, A.B., HOEFFEL, J.; SUAREZ, C. Parcerias Ambientais: diagnóstico turístico e propostas de educação ambiental em Vargem - SP, Projeto de Pesquisa de Políticas Públicas 06/51790-8, FAPESP, 2007.

GUNN, C.A. Tourism Planning: basics concepts cases. $4^{\text {th }}$ ed. London: Routledge, 2002.

HOEFFEL, J. L.; FADINI, A.A.B; MACHADO, M. K.; REIS, J.C. Trajetórias do Jaguary - a complexidade sócio-ambiental no Reservatório dos Rios Jaguary/Jacareí. Annals of Proceedings International Congress on Environmental Planning and Management. Brasília: Catholic University of Brasília, 2005, p. 1-16 (CD Rom).

IRVING, M.A.; BURSZTYN, I.; SANCHO A.P. Revisitando significados em sustentabilidade no planejamento turístico. Caderno Virtual de Turismo,v.5, n.4, p.1 -6, 2005.

ORGANIZAÇÃO MUNDIAL DO TURISMO - OMT. Introdução ao turismo. São Paulo: Roca, 2001.

POLES, G.; RABINOVICCI, A. O ambientalismo, o turismo e os dilemas do desenvolvimento sustentável. In: NEIMAN, Z.; RABINOVICI, A. Turismo e meio ambiente no Brasil. Barueri, SP: Manole, 2010. 
RUA, M.G. Turismo e políticas públicas de inclusão. In: Turismo social: diálogos do turismo, uma viagem de inclusão. Ministério do Turismo, Instituto Brasileiro de Administração Municipal. Rio de Janeiro: IBAM, 2006.

RUSCHMANN, D.V.N. Turismo e Planejamento Sustentável: a proteção do meio ambiente. Campinas: Papirus, 2008.

SÃO PAULO. Secretaria de Estado do Meio Ambiente. Atlas das Unidades de Conservação Ambiental do Estado de São Paulo. São Paulo: SMA, 2000.

SEABRA, G.F. Ecos do turismo: O turismo ecológico em áreas protegidas. Campinas: Papirus, 2001, p. 74, 220-221.

SILVA, A.C.Q.; TRAVASSOS, A.I.P.; BLANCO, C.R.F.; ARRUDA, C.C.; MARQUES, E.G.L.; PEGORARO, J.L. Vargem/SP- Meio Biológico. In: HOEFFEL, J. L. M. (org.). Ambiente de Vargem: diagnóstico crítico. Itatiba: Universidade São Francisco, p. 85-120, 1994.

Cristiane Ferraz e Silva Suarez: Universidade São Francisco, Bragança Paulista, SP, Brasil. Email: cristiane.suarez@saofrancisco.edu.br Link para o currículo Lattes: http://lattes.cnpq.br/7955383731847589

Nayra de Moraes Gonçalves: Moinho d'Água Treinamentos, Atibaia, SP, Brasil. Email: nayragoncalves@gmail.com Link para o currículo Lattes: http://lattes.cnpq.br/9703941932203592

João Luiz de Moraes Hoefel: Núcleo de Estudos em Sustentabilidade/Faculdades Atibaia (NES/FAAT), Atibaia, SP, Brasil.

Email: jlhoeffel@gmail.com

Link para o currículo Lattes: http://lattes.cnpq.br/7635072427530391

Data de submissão: 31 de maio de 2012

Data de recebimento de correções: 21 de junho de 2013

Data do aceite: 01 de julho de 2013

Avaliado anonimamente 